\title{
The Autism Simplex Collection: an international, expertly phenotyped autism sample for genetic and phenotypic analyses
}

Joseph D Buxbaum ${ }^{1 *}$, Nadia Bolshakova², Jessica M Brownfeld ${ }^{1}$, Richard JL Anney ${ }^{2}$, Patrick Bender ${ }^{3 \wedge}$, Raphael Bernier ${ }^{4}$, Edwin H Cook ${ }^{5}$, Hilary Coon ${ }^{6}$, Michael Cuccaro ${ }^{7}$, Christine M Freitag ${ }^{8}$, Joachim Hallmayer ${ }^{9}$, Daniel Geschwind ${ }^{10}$, Sabine M Klauck ${ }^{11}$, John I Nurnberger ${ }^{12}$, Guiomar Oliveira ${ }^{13,14}$, Dalila Pinto ${ }^{1}$, Fritz Poustka ${ }^{8}$, Stephen W Scherer ${ }^{15}$, Andy Shih ${ }^{16}$, James S Sutcliffe ${ }^{17,18}$, Peter Szatmari ${ }^{19}$, Astrid M Vicente ${ }^{20,21,22}$, Veronica Vieland ${ }^{23}$ and Louise Gallagher ${ }^{2 *}$

\begin{abstract}
Background: There is an urgent need for expanding and enhancing autism spectrum disorder (ASD) samples, in order to better understand causes of ASD.

Methods: In a unique public-private partnership, 13 sites with extensive experience in both the assessment and diagnosis of ASD embarked on an ambitious, 2-year program to collect samples for genetic and phenotypic research and begin analyses on these samples. The program was called The Autism Simplex Collection (TASC). TASC sample collection began in 2008 and was completed in 2010, and included nine sites from North America and four sites from Western Europe, as well as a centralized Data Coordinating Center.
\end{abstract}

Results: Over 1,700 trios are part of this collection, with DNA from transformed cells now available through the National Institute of Mental Health (NIMH). Autism Diagnostic Interview-Revised (ADI-R) and Autism Diagnostic Observation Schedule-Generic (ADOS-G) measures are available for all probands, as are standardized IQ measures, Vineland Adaptive Behavioral Scales (VABS), the Social Responsiveness Scale (SRS), Peabody Picture Vocabulary Test (PPVT), and physical measures (height, weight, and head circumference). At almost every site, additional phenotypic measures were collected, including the Broad Autism Phenotype Questionnaire (BAPQ) and Repetitive Behavior Scale-Revised (RBS-R), as well as the non-word repetition scale, Communication Checklist (Children's or Adult), and Aberrant Behavior Checklist (ABC). Moreover, for nearly 1,000 trios, the Autism Genome Project Consortium (AGP) has carried out lllumina 1 M SNP genotyping and called copy number variation (CNV) in the samples, with data being made available through the National Institutes of Health (NIH). Whole exome sequencing (WES) has been carried out in over 500 probands, together with ancestry matched controls, and this data is also available through the $\mathrm{NH}$. Additional WES is being carried out by the Autism Sequencing Consortium (ASC), where the focus is on sequencing complete trios. ASC sequencing for the first 1,000 samples (all from whole-blood DNA) is complete and data will be released in 2014. Data is being made available through NIH databases (database of Genotypes and Phenotypes (dbGaP) and National Database for Autism Research (NDAR)) with DNA released in Dist 11.0. Primary funding for the collection, genotyping, sequencing and distribution of TASC samples was provided by Autism Speaks and the NIH, including the National Institute of Mental Health (NIMH) and the National Human Genetics Research Institute (NHGRI).

Conclusions: TASC represents an important sample set that leverages expert sites. Similar approaches, leveraging expert sites and ongoing studies, represent an important path towards further enhancing available ASD samples.

\footnotetext{
* Correspondence: joseph.buxbaum@mssm.edu; lgallagh@tcd.ie

Deceased

${ }^{1}$ The Seaver Autism Center for Research and Treatment, Department of Psychiatry, Icahn School of Medicine at Mount Sinai, New York 10029, USA ${ }^{2}$ Autism Genetics Group, Department of Psychiatry, School of Medicine, Trinity College, Dublin 8, Ireland Additional TASC participants and complete author information are listed at the end of the article
}

\section{Biomed Central}

(c) 2014 Buxbaum et al.; licensee BioMed Central Ltd. This is an Open Access article distributed under the terms of the Creative Commons Attribution License (http://creativecommons.org/licenses/by/2.0), which permits unrestricted use, distribution, and reproduction in any medium, provided the original work is properly credited. 


\section{Background}

Autism spectrum disorder (ASD) is a highly heritable neurodevelopmental disorder characterized by fundamental deficits in social reciprocity and the presence of restricted interests and/or repetitive behaviors [1]. ASD is among the most prevalent of developmental disorders with an estimated prevalence of about 1 in 100, with males affected at a rate four times that of females [2]. A substantial portion of the risk for ASD traces to genetic variation, either inherited $[1,3,4]$ or arising de novo [5-11]. Through the strong support of families, advocacy groups and international research initiatives, large collaborative networks have been formed to advance knowledge of genes associated with ASD, and in recent years, these efforts have led to dramatic progress in the understanding of the genetics of ASD. Recent findings identify examples of specific etiological mechanisms, while underscoring the highly complex nature of the genetic architecture in ASD. To date, a specific genetic etiology can be identified in up to $25 \%$ of individuals with ASD and include single gene disorders (for example, Fragile X), known genetic syndromes (for example, 22q11 deletion syndrome), chromosomal anomalies, de novo and inherited copy number variation $(\mathrm{CNV})$, indels, and single nucleotide variation (SNV) [12]. Intensive behavioral interventions can have profoundly positive effects on the prognosis of autism (for example, see [13]), however morbidity and the cost of ASD to society, families and individuals remains high $[14,15]$, reinforcing the need for earlier diagnosis and ultimately, targeted treatment.

Further advances in the genetics of ASD will require analysis of genetic variation at all levels, necessitating the need to take advantage of new technology, including that of massively parallel (high-throughput) sequencing, and will require many thousands of samples to have adequate power to identify rare variants associated with high risk and more common variants associated with lower risk. The Interagency Autism Coordinating Committee (IACC) of the NIH, in its 2010 strategic plan, has called for genetic analysis of some 20,000 unrelated families, a number that is consistent with studies in other psychiatric disorders such as schizophrenia (which also has a similar prevalence and heritability to autism, see [16]). The IACC recognized that in order to discover additional causes of ASD to inform 'prognosis and treatments and lead to the prevention/preemption of the challenges and disabilities of ASD', the community would require such sample sizes.

In spite of the prevalence and burden of ASD, there have not yet been sufficient large-scale initiatives to recruit subjects to reach 20,000 unrelated families, and the numbers of unrelated families available to researchers through the National Institute of Mental Health (NIMH) Center for Collaborative Genetic Studies on Mental Disorders (CCGSMD) was still moderate in 2008. To begin to redress this, members of the Autism Genome Project Consortium (AGP) made a proposal to Autism Speaks to collect a large number of well-phenotyped trios and to make them publically available through the existing open process of the NIMH CCGSMD. The proposal attempted to be modest in terms of costs because all participating sites were already fully qualified on the relevant instruments, had families in clinical and research studies to turn to for participation, and all sites agreed to leverage ongoing studies funded by parallel sources to carry out the proposed sample collection at a fraction of the real costs. After positive review at Autism Speaks, and a critical parallel commitment by the NIMH to collect, transform, and distribute biomaterials and data through CCGSMD, The Autism Simplex Collection (TASC) was awarded funds to ascertain 1,700 trios in this initiative. As of today, the TASC samples are now available for qualified researchers through the NIMH CCGSMD and additional genotyping and whole exome sequencing (WES) data is being made available for these samples on an ongoing basis.

\section{The Autism Genome Project Consortium}

In 2004, through the support of the National Alliance for Autism Research (NAAR), now Autism Speaks, the AGP was launched as an international consortium of genetic researchers from North America and Europe dedicated to identifying genes that underlie susceptibility to ASD. The goal of the AGP was to identify causes of ASD using modern genetic approaches and to then translate these findings into better clinical practice. The members of the AGP have joined together to reach these goals, recognizing that an open collaborative structure would allow the field to proceed with maximal efficiency. While a detailed description of the AGP is beyond the scope of the current manuscript, it is important to highlight some recent successes as they inter-relate with the goals of the TASC. The AGP has consistently made use of state-of-the-art methods, describing for the first time a genome-wide assessment of $\mathrm{CNV}$ in ASD that included a first report of CNV at the NRXN1 gene in ASD [7]. The AGP reported a large genome-wide association study (GWAS) in ASD [17] and has identified many CNVs that contribute to ASD risk [6]. This latter study showed that CNV in genes previously associated with intellectual disability (ID) are likely contributing to ASD risk and identified pathways that appear to be implicated in ASD risk. The AGP collaborates with other initiatives, carrying out genotyping where requested (for example, see [18]) and providing all genotype data to the Psychiatric Genetics Consortium (PGC; [19]) for mega-analysis. Recently the AGP has completed genotyping another large sample (including much of TASC; Pinto et al. in press) and has contributed over 1,000 TASC samples for WES. WES data from cases was generated and 
analyzed, in a large effort funded by the NIMH and the National Human Genetics Research Institute (NHGRI), through an American Recovery and Reinvestment Act grant $[3,8,20,21]$. WES data from trios is now being generated by the ASC [22], again with support from the NIMH and NHGRI.

The AGP thus represents a unique union of organizations and research sites (over 50) that is comprised of clinicians and researchers with recognized expertise in ASD that work closely with local ASD groups and families. Since 2003, AGP members have published several hundred peer-reviewed papers on autism genetics research. The pooling of the extensive scientific and clinical expertise from across the world can serve to provide reliably characterized samples of phenotype and genotype data to the scientific community. This is critical as large, reliable samples are crucial for dissection of the genetic and genomic architecture of ASD.

\section{The Autism Simplex Collection (TASC)}

In 2008, the AGP sought to provide an independent ASD sample for gene discovery and phenotypic analyses, and for replicating and extending findings from prior studies carried out by the AGP and by additional research groups. To this end, 13 sites within the AGP with extensive experience in the diagnosis and assessment of ASD made a proposal that included recruitment of additional families to the NIMH CCGSMD in a two-year period. Recruitment would include in-depth expert phenotyping of all families and biomaterials from all families.

\section{Methods}

Autism Speaks agreed to fund the collection of 1,700 samples, while the NIH agreed to assume the costs for collecting, transforming and distributing the samples, as well as warehousing all clinical information. Dr. Louise Gallagher coordinated the recruitment with principle investigators at each site taking local responsibility (see Table 1). Inclusion criteria included individuals aged between 3 and 21 years with a research diagnosis of autism/ ASD based on the Autism Diagnostic Interview-Revised (ADI-R) and the Autism Diagnostic Observation Schedule (ADOS) (administered by research reliable raters). Individual IQs were preferably greater than or equal to 35 based on standardized testing and a full-scale or nonverbal mental age of 18 months or greater. Only full parent-child trios were included and the availability of an unaffected sibling was not a requirement for inclusion. Individuals with known medical or genetic causes of autism or a history consistent with Childhood Disintegrative Disorder were excluded. Other exclusion criteria included: extreme prematurity (<1,000 grams or less than 32 weeks); prematurity with associated neurological complications; birth
Table 1 Target The Autism Simplex Collection (TASC) sample contribution by site

\begin{tabular}{llll}
\hline Site & Year 1 & Year 2 & $\begin{array}{l}\text { Total } \\
\text { number } \\
\text { of trios }\end{array}$ \\
\hline $\begin{array}{l}\text { Portugal (AM Vicente and G Oliveira, } \\
\text { site co-PIs) }\end{array}$ & 183 & 97 & 280 \\
Mount Sinai (JD Buxbaum, site PI) & 125 & 106 & 231 \\
Ireland (L Gallagher, TASC PI and site PI) & 100 & 102 & 202 \\
Canada (P Szatmari, site PI) & 100 & 85 & 185 \\
Utah (H Coon, site PI) & 100 & 85 & 185 \\
Miami (M Cuccaro, site PI) & 100 & 76 & 176 \\
Vanderbilt Univ (JS Sutcliffe, site PI) & 70 & 59 & 129 \\
Frankfurt (CM Freitag and F Poustka site & 59 & 50 & 109 \\
Co-PIs) and Heidelberg (SM Klauck, site PI) & & & \\
AGRE (D Geschwind, site PI) & 50 & 42 & 92 \\
Indiana (JI Nurnberger, site PI) & 40 & 34 & 74 \\
Chicago (EH Cook, site PI) & 20 & 30 & 50 \\
CPEA (R Bernier, site PI) & 5 & 4 & 9 \\
Total & & & 1,719 \\
\hline
\end{tabular}

trauma with associated early neo-natal complications; significant brain injury; in utero exposure to medication known to be associated with autism, for example. retinoic acid, sodium valproate. The Phenotype Protocol was developed and agreed by the members of the AGP Phenotype Analytic Committee (Chair: Dr. Peter Szatmari). Additionally, consultation with the Simon Simplex Collection, which was also in a phase of phenotype protocol development, allowed for cross-comparability of some instruments. Core assessments carried out at all sites included ADI-R [23] and ADOS-G [24] for the probands, as well as standardized IQ measures, Vineland Adaptive Behavioral Scales (VABS) [25], Social Responsiveness Scale (SRS) [26], Peabody Picture Vocabulary Test (PPVT) [27] and physical measures (height, weight, and head circumference) (Table 2). In addition, at almost every site, additional phenotype measures were assessed, including the Broad Autism Phenotype Questionnaire (BAPQ) [28] and Repetitive Behavior Scale-Revised (RBS-R) [29], as well as the non-word repetition scale (from the Comprehensive Test of Phonological Processing/ CTOPP-Domain V) [30], The Children's Communication Checklist-2 [31], Communication Checklist-Adult Version [32], and Aberrant Behavior Checklist (ABC) [33] (Table 2). Phenotypes were uploaded to a centralized database in the Data Coordinating Center (DCC), which performed point-of-entry data validation, facilitated cross-site harmonization of clinical information, and provided combined output data for analysis to ensure a common starting point for analyses performed at different participating sites. 
Table 2 Phenotype measures in The Autism Simplex Collection (TASC) samples

\begin{tabular}{|c|c|c|c|c|c|c|c|c|c|c|c|c|}
\hline Additional Measures & AGRE & Canada & Chicago & Washington & Germany & Ireland & Miami & Portugal & Utah & Vanderbilt & $\begin{array}{l}\text { Mount } \\
\text { Sinai }\end{array}$ & Indiana \\
\hline ADI & Yes & Yes & Yes & Yes & Yes & Yes & Yes & Yes & Yes & Yes & Yes & Yes \\
\hline ADOS & Yes & Yes & Yes & Yes & Yes & Yes & Yes & Yes & Yes & Yes & Yes & Yes \\
\hline $\begin{array}{l}\text { Peabody Picture } \\
\text { Vocabulary Test (PPVT) }\end{array}$ & Yes & Yes & Yes & Yes & Yes & Yes & Yes & Yes & Yes & Yes & Yes & Yes \\
\hline Nonword repetition scale & No & Yes & Yes & Yes & No & Yes & Yes & Yes & Yes & Yes & Yes & Yes \\
\hline $\begin{array}{l}\text { Children's communication } \\
\text { checklist-2 }\end{array}$ & No & Yes & Yes & No & CCC-1 & Yes & No & Yes & Yes & Yes & Yes & Yes \\
\hline $\begin{array}{l}\text { Communication } \\
\text { checklist-adult }\end{array}$ & No & Yes & Yes & No & No & Yes & No & Yes & Yes & Yes & Yes & Yes \\
\hline Standardized measure of IQ & Yes & Yes & Yes & Yes & Yes & Yes & Yes & Yes & Yes & Yes & Yes & Yes \\
\hline $\begin{array}{l}\text { Vineland adaptive } \\
\text { behavior scales }\end{array}$ & Yes & Yes & Yes & Yes & Yes & Yes & Yes & Yes & Yes & Yes & Yes & Yes \\
\hline $\begin{array}{l}\text { Social responsiveness } \\
\text { scale }\end{array}$ & Yes & Yes & Yes & Yes & Yes & Yes & Yes & Yes & Yes & Yes & Yes & Yes \\
\hline BAPQ & No & Yes & Yes & Yes & No & Yes & No & Yes & Yes & Yes & Yes & Yes \\
\hline $\begin{array}{l}\text { Physical measures } \\
\text { (height, weight, } \\
\text { head circumference) }\end{array}$ & Yes & Yes & Yes & Yes & Yes & Yes & Yes & Yes & Yes & Yes & Yes & Yes \\
\hline $\begin{array}{l}\text { Repetitive behavior } \\
\text { scale-revised }\end{array}$ & Yes & Yes & Yes & Yes & No & Yes & Yes & Yes & Yes & Yes & Yes & Yes \\
\hline $\begin{array}{l}\text { Aberrant behavior } \\
\text { checklist }\end{array}$ & No & Yes & Yes & Yes & Yes & Yes & Yes & Yes & Yes & Yes & Yes & Yes \\
\hline
\end{tabular}

CCC-1, Children's Communication Checklist-1.

\section{Results}

The consortium recruited over $90 \%$ of its target sample in approximately two and a half years. The ambitious recruitment was made feasible by capitalizing on sites with active clinical and research programs, already utilizing standardized, research-quality evaluation methods, and by leveraging site-specific resources. The TASC collection includes a majority of European ancestry, but also includes samples of more diverse ancestry. Summary statistics on ancestry, as well as ADI-R and ADOS-G diagnoses, and available genetic data are shown Table 3.

\section{Discussion}

\section{Genetic analyses of TASC samples}

AGP members continue their work on ASD genetics and have been making use of TASC samples to this end. Over 400 TASC families are included in the two recent AGP papers reporting on $\mathrm{CNV}$ and common SNPs in ASD [6,17]. Additional TASC families are in the current analysis in the follow-up AGP cohort (Pinto et al., in press), such that to date, both genome-wide SNP data and CNV calls have been generated for some 900 TASC families. This data is being analyzed by the AGP and shared with other sites, including the PGC [19] as well as the database of Genotypes and Phenotypes (dbGaP) and the National Database for Autism Research (NDAR). Genotypes were managed and stored centrally in the
Table 3 Summary data The Autism Simplex Collection (TASC) sample

\begin{tabular}{|c|c|c|}
\hline & $\mathbf{N}$ & $\%$ \\
\hline \multicolumn{3}{|l|}{ Total sample } \\
\hline Individuals & 5444 & \\
\hline Families & 1719 & \\
\hline Children & 1997 & \\
\hline Male children & 1643 & 82.4 \\
\hline Female children & 354 & 17.8 \\
\hline \multicolumn{3}{|l|}{ Genetic data available } \\
\hline CNV data & 2666 & 49.0 \\
\hline GWA data & 2934 & 53.9 \\
\hline $\begin{array}{l}\text { Whole exome data (not including } \\
\text { ongoing ASC data) }\end{array}$ & 530 & 29.4 (cases only) \\
\hline \multicolumn{3}{|l|}{ GWA-derived ancestry } \\
\hline European & 2443 & 83.3 \\
\hline African & 66 & 2.2 \\
\hline Latino & 352 & 12.0 \\
\hline Asian & 73 & 2.5 \\
\hline \multicolumn{3}{|l|}{ Classification } \\
\hline ADI (ASD1 or ASD2 [34] or autism) & 1464 & \\
\hline ADI (autism) (subset of above counts) & 1339 & 91.5 \\
\hline ADOS (ASD or autism) & 1262 & \\
\hline ADOS (autism) (subset of above counts) & 1008 & 79.9 \\
\hline
\end{tabular}


DCC along with phenotypes and were transferred from there to the national databases. Called $\mathrm{CNV}$ are also available for TASC samples.

The TASC samples were also an important part of studies sequencing over 1,000 ASD exomes using next-generation sequencing. Five sites collaborated on this American Recovery and Reinvestment Act (ARRA)-funded initiative, where a premium was placed on making use of publically available samples that could be matched with control samples using genome-wide SNP data. Using genomewide SNP data generated by the AGP from the approximately 950 TASC families, over 500 unrelated TASC ASD subjects were selected for WES $[3,8,20,21]$. Sequencing data from these families were released early 2012 via $\mathrm{dbGaP}$. The same ARRA grant provided resources to facilitate the release of TASC samples to additional researchers through the NIMH CCGSMD. Most recently, the ASC [22] has begun to sequence whole blood-derived DNA from TASC samples, with support from the NIMH and NHGRI. WES data from 1,000 samples (primarily in the form of trios) will be released through dbGaP in 2014, and data from additional TASC samples will be released as the data become available.

\section{TASC in the broader context}

The goal identified by the IACC to examine 20,000 ASD probands for genetic factors is consistent with studies in other complex psychiatric disorders. As noted above, both prevalence and heritability of schizophrenia are in the same range as is seen for ASD [16]. In addition, like ASD, schizophrenia risk includes $\mathrm{CNV}$ as a source of the risk architecture [35,36]. The PGC has published a GWAS with approximately 18,000 schizophrenia samples and identified over 10 SNPs with very modest effect sizes [37], with a larger study (with twice the number of affecteds) now being completed. The PGC study in ASD, which includes all available SNP data in ASD (and virtually all AGP and TASC data) accounts for over 5,000 samples. Clearly it is not yet possible to identify multiple common SNPs with very low effect sizes are part of the ASD risk, as it is clear that common SNPs with odds ratios greater than 1.3 can be excluded [38]. Even considering rare variation with major effect, large sample sizes are needed, precisely because the variants are rare. In short, there is every reason to think that the target of 20,000 proposed by the IACC is required and that this sample size might begin to achieve the associated goal crucial of the IACC, which is to capture a significant proportion of the genetic risk for ASD.

TASC shares similarities with other large-scale sample collection. These include the Autism Genetic Resource Exchange (AGRE) [39], a network originally funded by Cure Autism Now (CAN) and now integrated into Autism Speaks, and the Simons Simplex Collection [40], funded by the Simons Foundation (see Table 4). In addition, the NIMH has samples from prior collections, and efforts are being made to collect additional samples. Collectively, these important efforts can provide samples that approach those in schizophrenia over the next several years and provide greater power for broader analyses that will be required to fully comprehend the relationship between genotype and phenotype.

\section{Conclusions}

There has been remarkable progress in ASD genetics in the past several years, driven to no small degree by the availability of large well-characterized samples. Relevant genetic findings can now be made in over $25 \%$ of ASD cases, using Fragile $\mathrm{X}$ testing, chromosome microarray (CMA) and WES. Fragile X testing and CMA can identify genetic findings in more than $10 \%$ of cases. With WES, studies in the past two years have shown that deleterious de novo, recessive and $\mathrm{X}$-linked mutations are observed in some $12 \%$ of subjects, and WES identifies small contributory $\mathrm{CNV}$ in some $7 \%$ of subjects $[3,4,8-11,41,42]$. Moreover, recently identified mutations and CNVs that are associated with high risk for ASD are leading to a better understanding of ASD pathogenesis and to model systems for ASD. Identification of highrisk genetic variants can provide an etiological diagnosis and opportunities for genetic counseling, an emerging important aspect in ASD care [43]. In some examples of monogenic forms of ASD, including Fragile X syndrome and tuberous sclerosis, model systems have led clinical

Table 4 Summary of available sample sets

\begin{tabular}{|c|c|c|c|}
\hline Sample set & $\begin{array}{l}\text { Approximate number } \\
\text { of unrelated samples }\end{array}$ & Design & Website \\
\hline TASC & 1,700 trios & $\begin{array}{l}\text { Simplex (no exclusion for additional } \\
\text { ASD in the family }\end{array}$ & \\
\hline AGRE & 1,700 families & Primarily multiplex & www.agre.org \\
\hline $\begin{array}{l}\text { Simons Simplex } \\
\text { Collection (SSC) }\end{array}$ & 2,500 quads & $\begin{array}{l}\text { Simplex with unaffected sib and no } \\
\text { additional ASD in first degree relatives }\end{array}$ & https://sfari.org/resources/simons-simplex-collection \\
\hline NIMH CCGSMD & $\begin{array}{l}15,000 \text { samples in current release } \\
\text { (with overlap with AGRE and TASC) }\end{array}$ & Multiple sources and designs & https://www.nimhgenetics.org/ \\
\hline
\end{tabular}


trials with novel therapeutics, highlighting the translational nature of gene discovery in ASD research. Explaining a large proportion of the genetic risk for ASD over the next five years is an achievable goal, but will require larger collections of well-characterized samples. The TASC research group and the TASC samples represent a successful collaboration and public-private partnership to enhance the numbers of samples available through the NIMH in less than three years. The phenotypic and genetic data generated by the AGP and others provide unique high value to this collection. Furthermore, the use of these samples in many ongoing studies will continue to add value to this collection. Similar approaches, leveraging expert sites and ongoing studies, represent an important path towards further enhancing the available ASD sample set.

\begin{abstract}
Abbreviations
ABC: Aberrant Behavior Checklist; ADI-R: Autism Diagnostic Interview-Revised; ADOS: Autism Diagnostic Observation Schedule; ADOS-G: Autism Diagnostic Observation Schedule-Generic; AGP: Autism Genome Project Consortium; AGRE: Autism Genetic Research Exchange; ARRA: American Recovery and Reinvestment Act; ASC: Autism Sequencing Consortium; ASD: autism spectrum disorder; BAPQ: Broad Autism Phenotype Questionnaire; CAN: Cure Autism Now; CCGSMD: Center for Collaborative Genetic Studies on Mental Disorders; CMA: chromosome microarray; CNV: copy number variation; CTOPP: Comprehensive Test of Phonological Processing; dbGaP: Database of Genotypes and Phenotypes; GWAS: genome-wide association study; IACC: Interagency Autism Coordinating Committee; ID: intellectual disability; NAAR: National Alliance for Autism Research; NDAR: National Database for Autism Research; NHGRI: National Human Genetics Research Institute: $\mathrm{NIH}$ : National Institutes of Health; NIMH: National Institute of Mental Health; PGC: Psychiatric Genetics Consortium; PPVT: Peabody Picture Vocabulary Test; RBS-R: Repetitive Behavior Scale-Revised; SNP: single-nucleotide polymorphism; SNV: single nucleotide variation; SRS: Social Responsiveness Scale; SSC: Simons Simplex Collection; TASC: The Autism Simplex Collection; VABS: Vineland Adaptive Behavioral Scales; WES: whole exome sequencing.
\end{abstract}

\section{Competing interest}

The authors declare that they have no competing interests.

\section{Authors' contributions}

JDB: conception and design; data collection; analysis; manuscript writing; critical revision; final approval of manuscript; overall study coordination; financial support. NB: overall study coordination. JMB: overall study coordination. RJLA: data collection; analysis; manuscript writing; critical revision; final approval of manuscript. PB: Patrick Bender is now deceased and therefore unable to read and approve the final version of the manuscript. RB: data collection. EHC: conception and design; data collection; analysis; manuscript writing; critical revision; final approval of manuscript; overall study coordination. HC: conception and design; data collection; analysis; final approval of manuscript; overall study coordination. MC: conception and design; data collection. CMF: data collection; critical revision; final approval of manuscript; overall study coordination. JH: conception and design. DG: final approval of manuscript; financial support. SMK: data collection; critical revision; final approval of manuscript; overall study coordination. JIN: data collection; critical revision; final approval of manuscript. GO: conception and design; data collection. DP: conception and design; analysis; manuscript writing; final approval of manuscript; overall study coordination; financial support. FP: data collection; critical revision; final approval of manuscript; overall study coordination. SWS: conception and design; data collection; final approval of manuscript; overall study coordination; financial support. AS: conception and design; financial support. JSS: conception and design; data collection; analysis; manuscript writing; final approval of manuscript; overall study coordination; financial support. PS: data collection; final approval of manuscript. AMV: data collection; final approval of manuscript; overall study coordination. W: conception and design; manuscript writing; final approval of manuscript; overall study coordination. LG: conception and design; data collection; analysis; manuscript writing; critical revision; overall study coordination; financial support. DG: data collection. AK: data collection; final approval of manuscript. LS: data collection; final approval of manuscript. AT: data collection. SB: data collection. GH: data collection. ML-S: data collection. FL: data collection. JMG: data collection. PC: data collection. SJG: data collection; final approval of manuscript. WMcM: overall study coordination. JM: data collection; analysis. JG: conception and design. MP-V: conception and design. ED: data collection. SS: data collection. CJMCD: data collection. DJP: data collection. JA: conception and design; data collection. GSC: data collection. JLH: conception and design; data collection. MP: data collection. ALN: data collection. CC: data collection. PF: conception and design. All authors read and approved the final manuscript.

\section{Acknowledgements}

The TASC consortium collection and genotyping was supported by Autism Speaks. Funding for the sequencing and distribution of TASC samples was provided by the National Institutes of Health (MH094303 and MH100233). We thank Dr. Bernie Devlin for thoughtful comments on the manuscript.

\section{Additional TASC participants are listed below}

David Grodberg, The Seaver Autism Center for Research and Treatment Department of Psychiatry, Icahn School of Medicine at Mount Sinai, New York 10029, USA.

Alexander Kolevzon, The Seaver Autism Center for Research and Treatment, Department of Psychiatry, Icahn School of Medicine at Mount Sinai, New York 10029, USA.

Latha Soorya, The Seaver Autism Center for Research and Treatment, Department of Psychiatry, Icahn School of Medicine at Mount Sinai, New York 10029, USA. Department of Psychiatry, Rush University Medical Center, Chicago, IL 60612, USA.

Ana Tryfon, The Seaver Autism Center for Research and Treatment, Department of Psychiatry, Icahn School of Medicine at Mount Sinai, New York 10029, USA. Present address: International Laboratory for Brain, Music, and Sound Research, University of Montreal and McGill University, Montreal, QC H3C 3J7, Canada. Sean Brennan, Autism Genetics Group, Department of Psychiatry, School of Medicine, Trinity College, Dublin 8, Ireland.

Gillian Hughes, Autism Genetics Group, Department of Psychiatry, School of Medicine, Trinity College, Dublin 8, Ireland.

Miriam Law-Smith, Autism Genetics Group, Department of Psychiatry, School of Medicine, Trinity College, Dublin 8, Ireland.

Frances Lombard, Autism Genetics Group, Department of Psychiatry, School of Medicine, Trinity College, Dublin 8, Ireland.

Jane McGrath, Autism Genetics Group, Department of Psychiatry, School of Medicine, Trinity College, Dublin 8, Ireland.

Philip Cali, Department of Educational Psychology, University of Washington, Seattle, WA, USA; University of Washington Autism Center, Box 357920,

Seattle, WA, USA.

Stephen J Guter, University of Illinois, Chicago, IL, USA.

William McMahon, Psychiatry Department, University of Utah Medical School, Salt Lake City, UT 84108, USA.

Judith Miller, Center of Autism Research, Children's Hospital of Philadelphia, Philadelphia, PA, USA.

Johnathan Gilbert, The John P Hussman Institute for Human Genomics,

University of Miami, Miami, FL 33101, USA.

Margaret Pericak-Vance, The John P Hussman Institute for Human Genomics, University of Miami, Miami, FL 33101, USA.

Eftichia Duketis, Department of Child and Adolescent Psychiatry,

Psychosomatics and Psychotherapy, JW Goethe University Frankfurt, 60528 Frankfurt, Germany.

Sabine Schlitt, Department of Child and Adolescent Psychiatry,

Psychosomatics and Psychotherapy, JW Goethe University Frankfurt, 60528 Frankfurt, Germany.

Christopher J McDougle, Department of Psychiatry, Indiana University School of Medicine, Indianapolis, IN 46202, USA.

David J Posey, Department of Psychiatry, Indiana University School of Medicine, Indianapolis, IN 46202, USA.

Joana Almeida, Instituto Nacional de Saúde Dr Ricardo Jorge, 1649-016 Lisbon, Portugal; Instituto Gulbenkian de Ciência, P-2781-901 Oeiras, Portugal; Hospital Pediátrico, 3000-602 Coimbra, Portugal. 
Amy L Nicholson, Department of Pediatrics, Vanderbilt University, Nashville, TN, USA

Catarina Correia, Instituto Nacional de Saúde Dr Ricardo Jorge, 1649-016 Lisbon, Portugal; Instituto Gulbenkian de Ciência, P-2781-901 Oeiras, Portugal. Genea S Crockett, Center for Human Genetics Research, Vanderbilt University, Nashville, TN, USA

Jonathan L Haines, Center for Human Genetics Research, Vanderbilt University, Nashville, TN, USA.

Melissa Potter, Center for Human Genetics Research, Vanderbilt University, Nashville, TN, USA

Penny Farrar, Wellcome Trust Center for Human Genetics, Oxford, UK.

\section{Author details}

${ }^{1}$ The Seaver Autism Center for Research and Treatment, Department of Psychiatry, Icahn School of Medicine at Mount Sinai, New York 10029, USA. ${ }^{2}$ Autism Genetics Group, Department of Psychiatry, School of Medicine, Trinity College, Dublin 8, Ireland. ${ }^{3}$ National Institute of Mental Health (NIMH), Bethesda, MD 20892-9663, USA. ${ }^{4}$ Department of Psychiatry and Behavioral Sciences, University of Washington, Seattle, WA 98195, USA. ${ }^{5}$ Institute for Juvenile Research, Department of Psychiatry, University of Illinois at Chicago, Chicago, IL 60608, USA. ${ }^{6}$ Psychiatry Department, University of Utah Medical School, Salt Lake City, UT 84108, USA. ${ }^{7}$ The John P Hussman Institute for Human Genomics, University of Miami, Miami, FL 33101, USA. ${ }^{8}$ Department of Child and Adolescent Psychiatry, Psychosomatics and Psychotherapy, JW Goethe University Frankfurt, 60528 Frankfurt, Germany. ${ }^{9}$ Department of Psychiatry and Behavioral Science, Child and Adolescent Psychiatry, Stanford School of Medicine, Stanford, CA, USA. ${ }^{10}$ Department of Neurology, University of California at Los Angeles, School of Medicine, Los Angeles, CA 90095, USA. ${ }^{11}$ German Cancer Research Center (DKFZ), 69120 Heidelberg, Germany. ${ }^{12}$ Department of Psychiatry, Indiana University School of Medicine, Indianapolis, IN 46202, USA. ${ }^{13}$ Unidade de Neurodesenvolvimento e Autismo do Serviço do Centro de Desenvolvimento da Criança and Centro de Investigação e Formação Clinica, Pediatric Hospital, Centro Hospitalar e Universitário de Coimbra, 3000-602 Coimbra, Portugal. ${ }^{14}$ University Clinic of Pediatrics and Institute for Biomedical Imaging and Life Science, Faculty of Medicine, University of Coimbra, 3000-602 Coimbra, Portugal. ${ }^{15}$ Department of Molecular Genetics, The Centre for Applied Genomics, Hospital for Sick Children and McLaughlin Centre and University of Toronto, Toronto, ON, Canada. ${ }^{16}$ Autism Speaks, New York, NY 10016, USA. ${ }^{17}$ Department of Molecular Physiology and Biophysics, Vanderbilt Kennedy Center, Vanderbilt University, Nashville, TN 37232, USA. ${ }^{18}$ Centers for Human Genetics Research and Molecular Neuroscience, Vanderbilt University, Nashville, TN 37232, USA. ${ }^{19}$ Department of Psychiatry and Behavioural Neurosciences, McMaster University, Hamilton, ON L8N 3Z5, Canada. ${ }^{20}$ Instituto Nacional de Saúde Dr Ricardo Jorge, 1649-016 Lisbon, Portugal. ${ }^{21}$ Instituto Gulbenkian de Ciência, P-2781-901 Oeiras, Portugal. ${ }^{22}$ BioFIG-Center for Biodiversity, Functional \& Integrative Genomics, Campus da FCUL, C2.2.12, Campo Grande, 1749-016 Lisboa, Portugal. ${ }^{23}$ The Research Institute at Nationwide Children's Hospital, The Ohio State University, Columbus, OH, USA.

Received: 5 June 2012 Accepted: 11 April 2014

Published: 20 May 2014

\section{References}

1. Veenstra-Vanderweele J, Christian SL, Cook EH Jr: Autism as a paradigmatic complex genetic disorder. Annu Rev Genomics Hum Genet 2004, 5:379-405.

2. Prevalence of autism spectrum disorders - Autism and Developmental Disabilities Monitoring Network, United States, 2006. MMWR Surveill Summ 2009, 58(10):1-20.

3. Lim ET, Raychaudhuri S, Sanders SJ, Stevens C, Sabo A, MacArthur DG, Neale BM, Kirby A, Ruderfer DM, Fromer M, Lek M, Liu L, Flannick J, Ripke S, Nagaswamy U, Muzny D, Reid JG, Hawes A, Newsham I, Wu Y, Lewis L, Dinh H, Gross S, Wang LS, Lin CF, Valladares O, Gabriel SB, dePristo M, Altshuler DM, Purcell SM, et al: Rare complete knockouts in humans: population distribution and significant role in autism spectrum disorders. Neuron 2013, 77(2):235-242.

4. Yu TW, Chahrour MH, Coulter ME, Jiralerspong S, Okamura-lkeda K, Ataman B, Schmitz-Abe K, Harmin DA, Adli M, Malik AN, D'Gama AM, Lim ET, Sanders SJ, Mochida GH, Partlow JN, Sunu CM, Felie JM, Rodriguez J, Nasir RH, Ware J, Joseph RM, Hill RS, Kwan BY, Al-Saffar M, Mukaddes NM, Hashmi A, Balkhy S, Gascon GG, Hisama FM, LeClair E, et al: Using whole-exome sequencing to identify inherited causes of autism. Neuron 2013, 77(2):259-273.
5. Glessner JT, Wang K, Cai G, Korvatska O, Kim CE, Wood S, Zhang H, Estes A, Brune CW, Bradfield JP, Imielinski M, Frackelton EC, Reichert J, Crawford EL, Munson J, Sleiman PM, Chiavacci R, Annaiah K, Thomas K, Hou C, Glaberson W, Flory J, Otieno F, Garris M, Soorya L, Klei L, Piven J, Meyer KJ, Anagnostou E, Sakurai T, et al: Autism genome-wide copy number variation reveals ubiquitin and neuronal genes. Nature 2009, 459(7246):569-573.

6. Pinto D, Pagnamenta AT, Klei L, Anney R, Merico D, Regan R, Conroy J, Magalhaes TR, Correia C, Abrahams BS, Almeida J, Bacchelli E, Bader GD, Bailey AJ, Baird G, Battaglia A, Berney T, Bolshakova N, Bölte S, Bolton PF, Bourgeron T, Brennan S, Brian J, Bryson SE, Carson AR, Casallo G, Casey J, Chung BH, Cochrane $\mathrm{L}$, Corsello C, et al: Functional impact of global rare copy number variation in autism spectrum disorders. Nature 2010, 466(7304):368-372.

7. Autism Genome Project Consortium, Szatmari P, Paterson AD, Zwaigenbaum L, Roberts W, Brian J, Liu XQ, Vincent JB, Skaug JL, Thompson AP, Senman L, Feuk L, Qian C, Bryson SE, Jones MB, Marshall CR, Scherer SW, Vieland VJ, Bartlett C, Mangin LV, Goedken R, Segre A, Pericak-Vance MA, Cuccaro ML, Gilbert JR, Wright HH, Abramson RK, Betancur C, Bourgeron T, Gillberg C, et al: Mapping autism risk loci using genetic linkage and chromosomal rearrangements. Nat Genet 2007, 39(3):319-328.

8. Neale BM, Kou Y, Liu L, Ma'ayan A, Samocha KE, Sabo A, Lin CF, Stevens C, Wang LS, Makarov V, Polak P, Yoon S, Maguire J, Crawford EL, Campbell NG, Geller ET, Valladares O, Schafer C, Liu H, Zhao T, Cai G, Lihm J, Dannenfelser R, Jabado O, Peralta Z, Nagaswamy U, Muzny D, Reid JG, Newsham I, Wu Y, et al: Patterns and rates of exonic de novo mutations in autism spectrum disorders. Nature 2012, 485(7397):242-245.

9. Sanders SJ, Murtha MT, Gupta AR, Murdoch JD, Raubeson MJ, Willsey AJ, Ercan-Sencicek AG, DiLullo NM, Parikshak NN, Stein JL, Walker MF, Ober GT, Teran NA, Song Y, El-Fishawy P, Murtha RC, Choi M, Overton JD, Bjornson RD, Carriero NJ, Meyer KA, Bilguvar K, Mane SM, Sestan N, Lifton RP, Günel M, Roeder K, Geschwind DH, Devlin B, State MW, et al: De novo mutations revealed by whole-exome sequencing are strongly associated with autism. Nature 2012, 485(7397):237-241.

10. O'Roak BJ, Vives L, Girirajan S, Karakoc E, Krumm N, Coe BP, Levy R, Ko A, Lee C, Smith JD, Turner EH, Stanaway IB, Vernot B, Malig M, Baker C, Reilly B, Akey JM, Borenstein E, Rieder MJ, Nickerson DA, Bernier R, Shendure J, Eichler EE, et al: Sporadic autism exomes reveal a highly interconnected protein network of de novo mutations. Nature 2012, 485(7397):246-250.

11. Iossifov I, Ronemus M, Levy D, Wang Z, Hakker I, Rosenbaum J, Yamrom B, Lee YH, Narzisi G, Leotta A, Kendall J, Grabowska E, Ma B, Marks S, Rodgers L, Stepansky A, Troge J, Andrews P, Bekritsky M, Pradhan K, Ghiban E, Kramer M, Parla J, Demeter R, Fulton LL, Fulton RS, Magrini VJ, Ye K, Darnell JC, Darnell RB, et al: De novo gene disruptions in children on the autistic spectrum. Neuron 2012, 74(2):285-299.

12. Betancur C: Etiological heterogeneity in autism spectrum disorders: more than 100 genetic and genomic disorders and still counting. Brain Res 2010, doi: 10.1016/j.brainres.2010.11.078.

13. Dawson G, Rogers S, Munson J, Smith M, Winter J, Greenson J, Donaldson A, Varley J: Randomized, controlled trial of an intervention for toddlers with autism: the Early Start Denver Model. Pediatrics 2010, 125(1):e17-e23.

14. Ganz ML: The lifetime distribution of the incremental societal costs of autism. Arch Pediatr Adolesc Med 2007, 161(4):343-349.

15. Knapp M, Romeo R, Beecham J: Economic cost of autism in the UK. Autism 2009, 13(3):317-336.

16. Sullivan PF: Schizophrenia genetics: the search for a hard lead. Curr Opin Psychiatry 2008, 21(2):157-160.

17. Anney R, Klei L, Pinto D, Regan R, Conroy J, Magalhaes TR, Correia C, Abrahams BS, Sykes N, Pagnamenta AT, Almeida J, Bacchelli E, Bailey AJ, Baird G, Battaglia A, Berney T, Bolshakova N, Bölte S, Bolton PF, Bourgeron T, Brennan S, Brian J, Carson AR, Casallo G, Casey J, Chu SH, Cochrane L, Corsello C, Crawford EL, Crossett A, et al: A genome-wide scan for common alleles affecting risk for autism. Hum Mol Genet 2010, 19(20):4072-4082.

18. Weiss LA, Arking DE, Daly MJ, Chakravarti A: A genome-wide linkage and association scan reveals novel loci for autism. Nature 2009, 461(7265):802-808.

19. Psychiatric GWAS Consortium Coordinating Committee, Cichon S, Craddock N, Daly M, Faraone SV, Gejman PV, Kelsoe J, Lehner T, Levinson DF, Moran A, Sklar P, Sullivan PF: Genomewide association studies: history, rationale, and prospects for psychiatric disorders. Am J Psychiatry 2009, 166(5):540-556.

20. Liu L, Sabo A, Neale BM, Nagaswamy U, Stevens C, Lim E, Bodea CA, Muzny D, Reid JG, Banks E, Coon H, Depristo M, Dinh H, Fennel T, Flannick J, Gabriel S, Garimella K, Gross S, Hawes A, Lewis L, Makarov V, Maguire J, Newsham I, Poplin R, Ripke S, Shakir K, Samocha KE, Wu Y, Boerwinkle E, Buxbaum JD, et al: 
Analysis of rare, exonic variation amongst subjects with autism spectrum disorders and population controls. PLoS Genet 2013, 9(4):e1003443.

21. He X, Sanders SJ, Liu L, De Rubeis S, Lim ET, Sutcliffe JS, Schellenberg GD, Gibbs RA, Daly MJ, Buxbaum JD, State MW, Devlin B, Roeder K: Integrated model of de novo and inherited genetic variants yields greater power to identify risk genes. PLoS Genet 2013, 9(8):e1003671.

22. Buxbaum JD, Daly MJ, Devlin B, Lehner T, Roeder K, State MW: The autism sequencing consortium: large-scale, high-throughput sequencing in autism spectrum disorders. Neuron 2012, 76(6):1052-1056.

23. Lord C, Rutter M, Le Couteur A: Autism Diagnostic Interview-Revised: a revised version of a diagnostic interview for caregivers of individuals with possible pervasive developmental disorders. J Autism Dev Disord 1994, 24(5):659-685.

24. Lord C, Risi S, Lambrecht L, Cook EH Jr, Leventhal BL, DiLavore PC, Pickles A, Rutter M: The autism diagnostic observation schedule-generic: a standard measure of social and communication deficits associated with the spectrum of autism. J Autism Dev Disord 2000, 30(3):205-223.

25. Sparrow SS, Cicchetti DV, Balla DA: Vineland-II: Vineland Adaptive Behavior Scales. 2nd edition. Circle Pines, MN: AGS Publishing; 2005.

26. Constantino JN: The Social Responsiveness Scale. Los Angeles, CA: Western Psychological Services; 2002.

27. Dunn LM: Peabody Picture Vocabulary Test 3rd edition. Circle Pines, MN: American Guidance Service; 1997.

28. Hurley RS, Losh M, Parlier M, Reznick JS, Piven J: The broad autism phenotype questionnaire. J Autism Dev Disord 2007, 37(9):1679-1690.

29. Lam KS, Aman MG: The Repetitive Behavior Scale-Revised: independent validation in individuals with autism spectrum disorders. J Autism Dev Disord 2007, 37(5):855-866

30. Wagner R, Torgesen J, Rashotte C: The Comprehensive Test of Phonological Processing. Austin, TX: Pro-ed; 1999.

31. Norbury CF, Nash M, Baird G, Bishop D: Using a parental checklist to identify diagnostic groups in children with communication impairment: a validation of the Children's Communication Checklist-2. Int J Lang Commun Disord 2004, 39(3):345-364.

32. Whitehouse AJ, Coon H, Miller J, Salisbury B, Bishop DV: Narrowing the broader autism phenotype: a study using the Communication ChecklistAdult Version (CC-A). Autism 2010, 14(6):559-574.

33. Aman MG, Singh NN, Stewart AW, Field CJ: The aberrant behavior checklist: a behavior rating scale for the assessment of treatment effects. Am J Ment Defic 1985, 89(5):485-491.

34. Risi S, Lord C, Gotham K, Corsello C, Chrysler C, Szatmari P, Cook EH Jr, Leventhal BL, Pickles A: Combining information from multiple sources in the diagnosis of autism spectrum disorders. J Am Acad Child Adolesc Psychiatry 2006, 45(9):1094-1103.

35. Merikangas AK, Corvin AP, Gallagher L: Copy-number variants in neurodevelopmental disorders: promises and challenges. Trends Genet 2009, 25(12):536-544.

36. Stankiewicz P, Lupski JR: Structural variation in the human genome and its role in disease. Annu Rev Med 2010, 61:437-455.

37. Ripke S, Sanders AR, Kendler KS, Levinson DF, Sklar P, Holmans PA, Lin DY, Duan J, Ophoff RA, Andreassen OA, Scolnick E, Cichon S, St Clair D, Corvin A, Gurling H, Werge T, Rujescu D, Blackwood DH, Pato CN, Malhotra AK, Purcell S, Dudbridge F, Neale BM, Rossin L, Visscher PM, Posthuma D, Ruderfer DM, Fanous A, Stefansson H, Steinberg S, et al: Genome-wide association study identifies five new schizophrenia loci. Nat Genet 2011 43(10):969-976.

38. Devlin B, Melhem N, Roeder K: Do common variants play a role in risk for autism? Evidence and theoretical musings. Brain Res 2010, doi: 10.1016/j. brainres.2010.11.026.

39. Lajonchere $\mathrm{CM}$ : Changing the landscape of autism research: the autism genetic resource exchange. Neuron 2010, 68(2):187-191.

40. Fischbach GD, Lord C: The Simons Simplex Collection: a resource for identification of autism genetic risk factors. Neuron 2010, 68(2):192-195.

41. Poultney CS, Goldberg AP, Drapeau E, Kou Y, Harony-Nicolas H, Kajiwara Y, De Rubeis S, Durand S, Stevens C, Rehnström K, Palotie A, Daly MJ, Ma'ayan A, Fromer M, Buxbaum JD, et al: Identification of small exonic CNV from whole-exome sequence data and application to autism spectrum disorder. Am J Hum Genet 2013, 93(4):607-619.

42. Krumm N, O'Roak BJ, Karakoc E, Mohajeri K, Nelson B, Vives L, Jacquemont S, Munson J, Bernier R, Eichler EE: Transmission disequilibrium of small CNVs in simplex autism. Am J Hum Genet 2013, 93(4):595-606.
43. Miller DT, Adam MP, Aradhya S, Biesecker LG, Brothman AR, Carter NP, Church DM, Crolla JA, Eichler EE, Epstein CJ, Faucett WA, Feuk L, Friedman JM, Hamosh A, Jackson L, Kaminsky EB, Kok K, Krantz ID, Kuhn RM, Lee C, Ostell JM, Rosenberg C, Scherer SW, Spinner NB, Stavropoulos DJ, Tepperberg JH, Thorland EC, Vermeesch JR, Waggoner DJ, Watson MS, et al: Consensus statement: chromosomal microarray is a first-tier clinical diagnostic test for individuals with developmental disabilities or congenital anomalies. Am J Hum Genet 2010, 86(5):749-764.

doi:10.1186/2040-2392-5-34

Cite this article as: Buxbaum et al:: The Autism Simplex Collection: an international, expertly phenotyped autism sample for genetic and phenotypic analyses. Molecular Autism 2014 5:34.

\section{Submit your next manuscript to BioMed Central and take full advantage of:}

- Convenient online submission

- Thorough peer review

- No space constraints or color figure charges

- Immediate publication on acceptance

- Inclusion in PubMed, CAS, Scopus and Google Scholar

- Research which is freely available for redistribution

Submit your manuscript at www.biomedcentral.com/submit
C Biomed Central 